\title{
Building Reconstruction of Historical and Cultural Protection Area Based on Green Technology
}

\author{
Zheng Jiaoyan*, Chen Hong \\ Email address: \\ 493634195@qq.com (Zheng Jiaoyan) \\ ${ }^{*}$ Corresponding author
}

School of Architecture and Urban Planning, Huazhong University of Science and Technology, Wuhan, China

\section{To cite this article:}

Zheng Jiaoyan, Chen Hong. Building Reconstruction of Historical and Cultural Protection Area Based on Green Technology. Science Discovery. Vol. 9, No. 5, 2021, pp. 206-212. doi: 10.11648/j.sd.20210905.12

Received: August 24, 2021; Accepted: September 11, 2021; Published: September 23, 2021

\begin{abstract}
With the continuous intensification of urban expansion, the transformation and utilization of existing building resources has gradually attracted attention from all walks of life. The Lifen building is the epitome of Wuhan's residential culture for nearly a century. After the baptism of time, the use function and structural safety of the Lifen building can no longer meet people's living needs today. Therefore, further research is needed on how to combine the protection and renovation of the Lifen building. This article takes Kunhouli, Jiang'an District, Wuhan as an example. Through field research and semi-open interviews with local residents, it is found that the current Kunhouli has poor thermal comfort, traffic congestion, outdated infrastructure, and lack of public space. And poor construction quality. According to the regional and cultural characteristics of Lifen, combined with the concept of green building and green analysis software, it is updated and transformed to promote the protection of Lifen while improving the living environment of Lifen, providing reference for the development of Wuhan Lifen's building renovation.
\end{abstract}

Keywords: Lifen, Residential Buildings, Renovation of Existing Buildings, Protection and Renewal

\section{里分建筑的绿色更新与改造策略研究}

\author{
郑娇艳"，陈宏 \\ 华中科技大学建筑与城市规划学院, 武汉, 中国 \\ 邮箱 \\ 493634195@qq.com (郑娇绝)
}

\begin{abstract}
摘要：随着城市扩张的不断加剧, 既有建筑资源的改造利用也逐渐受到社会各界的关注。里分建筑是武汉近一个世纪 住宅文化的缩影, 历经时间的洗礼, 里分建筑的使用功能和结构安全已经不能满足人们如今的生活需求。故有待进一 步研究如何将里分建筑的保护和改造结合。本文以武汉市江岸区坤厚里为例, 通过实地调研, 对当地住户进行半开放 式访谈, 发现当前坤厚里存在热舒适环境较差、交通拥堵、基础设施老旧、公共空间缺乏及建筑质量较差等问题。根 据里分的地域特征和文化特点, 结合绿色建筑理念和绿色分析软件进行更新改造, 促进里分的保护同时改善里分的寓 居环境, 为武汉里份建筑改造发展提供参考意见。
\end{abstract}

关键词：里分, 居住建筑, 既有建筑改造, 保护更新 


\section{1. 引言}

既有建筑的绿色更新与改造是如今实现城市可持续 发展的重要战略措施。十三五计划中明确指出: 对既有居 住建筑绿色节能改造, 实施改造面积 5 亿平方米以上 [1]。 我国既有建筑存量高, 大量历史街区及传统居住建筑成为 滞碍城市发展转型的一大因素, 面临着被废弃和拆除的命 运。里分是武汉独特的传统民居建筑形式, 作为城市历史 变迁和地方文化的载体, 其建筑文化和人文特点都具有巨 大的研究价值。现存的里分大多为武汉的历史保护街区, 废弃和拆除无疑是对城市文化的一种破坏, 同时进一步加 大了能源浪费。由此看来, 对里分建筑的更新与改造迫在 眉睫。已有大量学者对里分的改造更新做了研究, 如王海 香结合低影响开发理念, 提出了对武汉泰兴里居住空间的 改造与更新策略[2]。王刚以武汉三德里为例, 提出了若干 里分建筑保护更新的策略[3]。张念伟等以遗产保护为角度, 研究了里分建筑的保护与更新策略 [4]。张文静基于BIM信 息化技术对于咸安坊建筑进行应用研究[5]。杨洋从街区形 态、目标人群、行为模式等作为切入点, 进行新旧关系整 合设计 [6]。但是较少学者基于绿色理念对里分建筑进行更 新改造。

所谓绿色更新改造, 即在评价和设计过程中综合考虑 “资源节约”、“节能环保”、“因地制宜”等绿色理念。本文 通过实地调研, 从历史街区及建筑的综合整治、功能提升、 资源节约、节能环保等角度, 发现里分建筑存在的具体居 住问题，进而进行绿色更新与改造。

\section{2. 里分建筑现状}

\section{1. 里分建筑现状}

坤厚里建于上个世纪初, 位于武汉汉口一元路历史文 化保护街区, 南临一元路, 北接一元小路, 东西分别紧临 胜利街和中山大道 (图1)。里分内部建筑由一条贯穿东 西的主要巷道及若干次巷进行连接, 主次巷道间的连接形 似鱼骨状 (图2), 其中主巷宽约 $6 \mathrm{~m}$, 前、后次巷宽 $1.5-3 \mathrm{~m}$ 。 巷道作为里分的主要通行道路, 同时还承载着居民的日常 生活。主巷可以承接较为丰富的日常娱乐休闲文化活动, 前、后次巷多为家庭宅前劳作或是邻里聊天的场所。里分 建筑多为居住建筑, 几栋独栋历史建筑被改为办公建筑, 临一元路和中山大道分布了后期建造的简易房用作零售 商业（图3）。里分内人口构成为原有住户和外来租赁人 员，其中后者占大多数，年龄构成以老年人居多[7]。

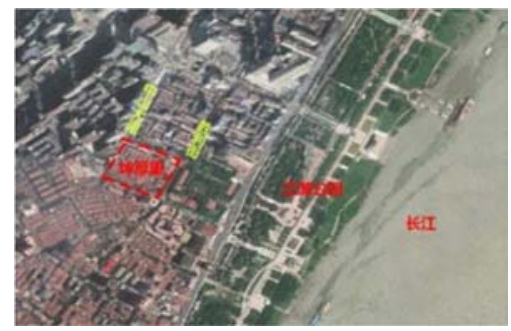

图1 坤厚里片区区位图（图片来源：作者自绘）。

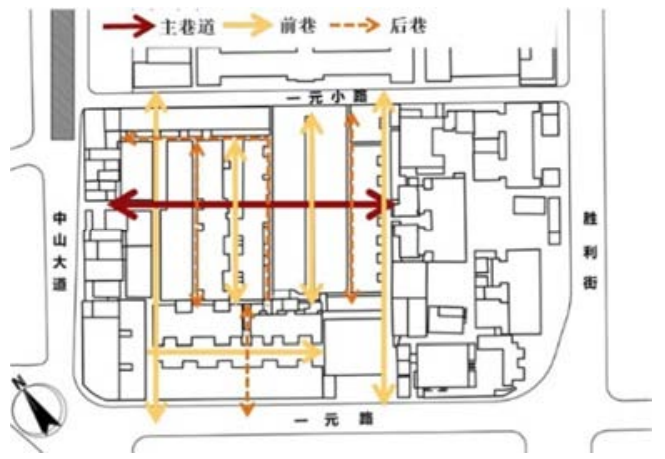

图2 坤厚里片区内部道路分析图（图片来源：作者自绘）。

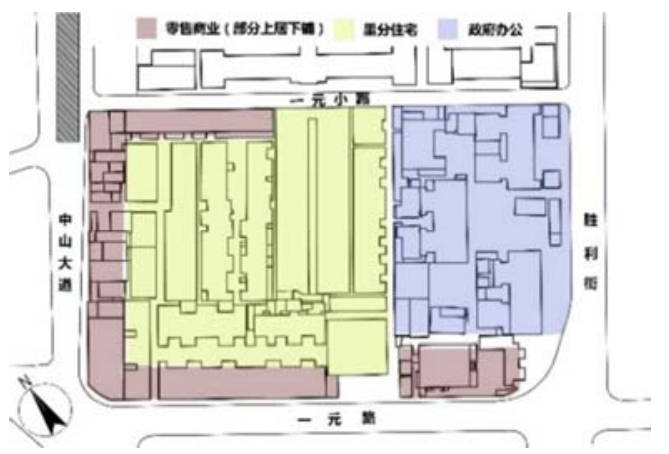

图3 坤厚里片区功能分析图（图片来源：作者自绘）。

\section{2. 里分建筑存在的问题}

随着城市的快速发展和不断更新, 里分的居住条件已 经不能满足居住的需求。根据调研走访, 发现坤厚里存在 以下问题:

(1) 环境质量差

(1)自主加建改建导致环境零乱不堪。里分原住民大多 搬走, 外来租赁人口占比高, 原来独门独户的住宅承载着 多户多辈的使用需求，因此卧室、㴻房、则所等基本空间 严重不足。高密度的居住人口使得居民们通过各种方式对 住宅进行不同程度的自发改造以满足居住的需求。居民往 往会在巷道、屋顶、住宅入口处、公共楼梯的下部、门窗 外部等处进行自主加建改建, 来缓解室内居住空间不足的 问题（图4）。在调研过程中发现很多居民会在宅前门的 公共空间后从事烹㳋、洗衣、种植等活动。自主搭建让里 分内的整体居住环境显得十分零乱, 其次加建部分对相邻 建筑也存在采光遮挡。

(2)围墙及加建建筑导致室外热舒适环境较差。坤厚里 建筑密度高, 在坤厚里外围区域局部建有围墙使得里分内 较为闭塞, 阻挡了空气的流入, 同时巷道的加建部分和堆 积的杂物使得内部空气不流通。在武汉夏季高温高湿的环 境下, 空气不流畅会使人体舒适度变差, 甚至产生头晕胸 闪等一系类不良反应。

(2) 交通出行拥堵

里分环境较为封闭, 仅有少数几个出入口。调研过程 中发现, 场地内停车位较为紧缺, 部分居民为了便利会将 机动车随停在里分出入口处 (图5)。此外电动车和共享 单车等非机动车辆也会随意停放在主巷道两边和次巷入 
户处, 加上居民的日常物品对公共空间的自主占用, 形成 了一种拥堵且无序的通行环境。

（3）公共空间和设施缺失

(1)里分内由于用地紧凑且功能单一, 居民日常娱乐休 闲的室外活动场所较为缺乏, 也没有集中的室内活动室。 目前仅有主巷空间和较为宽敞的次巷, 可作为人们公共活 动的场所, 但是这些主次巷存在较多消极的空间, 或是长 满杂草缺乏管理, 或是堆砌私人物品凌乱不堪。

(2)里分内基础设施年代久远, 无法与不断发展进步的 生活方式相匹配。较为突出的是晾晒设施及空间较为贵乏, 居民大多自主张拉绳索进行晾晒或是直接将衣物晒在电 线上 (图6), 这种行为带来了较大的安全隐患。同时休 闲座椅、景观设施、垃圾集中处理站等设施的配套也严重 不足, 调研过程中有较多的居民反应垃圾回收不及时造成 的环境污染问题。

（4）建筑外围护结构质量差

里分建筑历史较为悠久, 受到自然环境因素的影响, 建筑主体结构、围护结构、建筑细部等变得老旧甚至存在 质量安全的隐患。部分建筑在建造时没有设置防潮层或是 防潮层老化, 导致部分墙面长毛发霉（图7）, 甚至出现 壁面起壳、脱落的情况, 门窗也出现了不同程度的老旧和 损坏。坤厚里由于建设年代早保温节能的标准也相对较低, 建筑内部能耗较大, 需要对外围护结构进行节能改造。

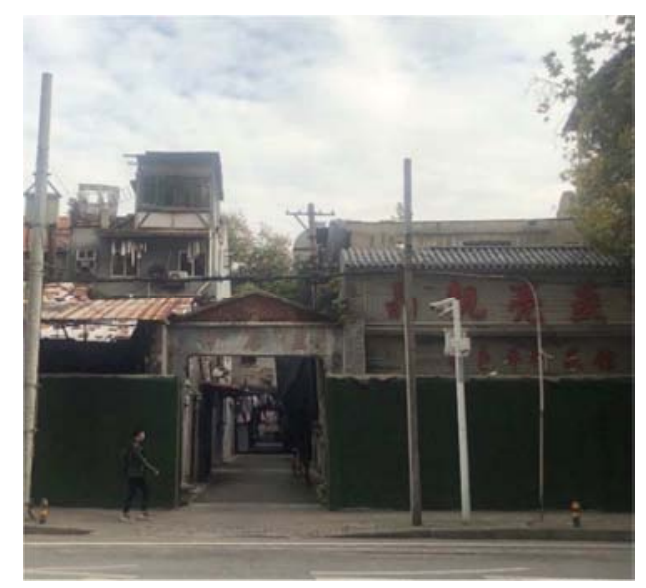

图4 屋顶自主加建（图片来源：作者自摄）。

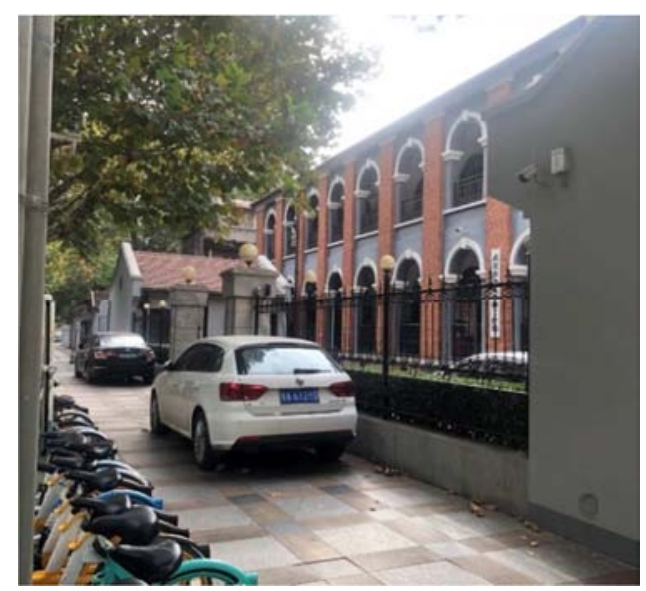

图5 路边随停占用人行通道（图片来源：作者自摄）。

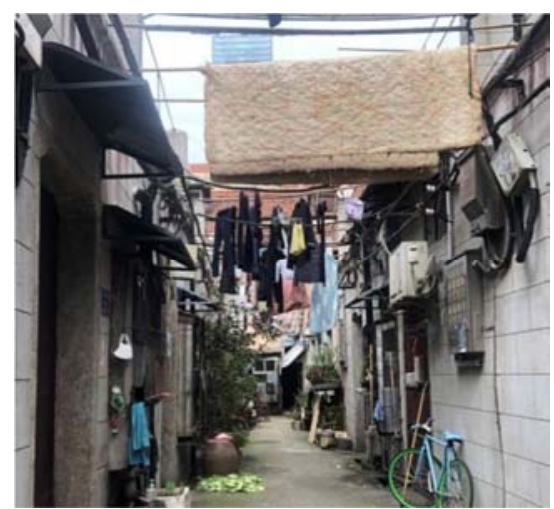

图6 堆满物品的巷道（图片来源：作者自摄）。

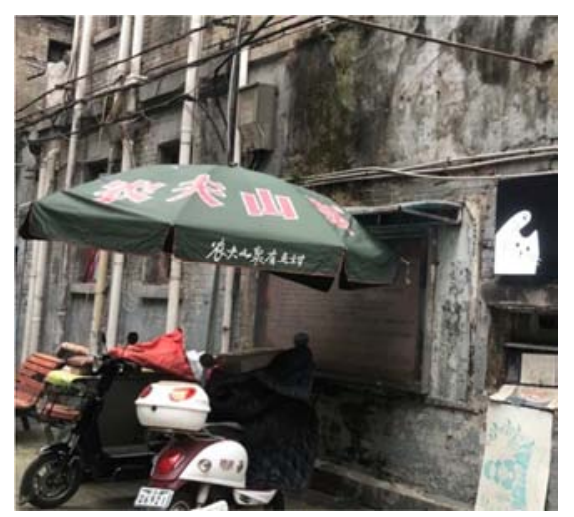

图7 墙体受潮出现大量污渍（图片来源：作者自摄）。

\section{3. 更新改造策略}

对于里分建筑的绿色更新与改造, 要注重对原有街区 和建筑的“原真性”保护和“整体性”保护。“原真性”保护即 要对其原有的格局、结构和空间做最大限度的保存, 在其 历史风貌和建筑特色不被破坏的前提下, 通过合理的设计, 使新技术与旧元素产生碰撞和对话, 使闲置或面临淘汰的 历史建筑的功能得到延续或者发挥新的功能, 延长传统建 筑的生命周期 [8]。“整体性”保护即将里份建筑作为一个整 体, 不仅要保护历史建筑、空间肌理等实体特征, 还可纳 入周边地区的整体环境中, 保护居民的交流交往的社会网 络[9]。

\section{1. 环境质量的改造}

（1）整治环境。首先, 采用分区责任制让居民对里 分的卫生维护进行自治管理。其次, 合理拆除自主搭建的 部分、还原空间和结构（图8）。通过以上两种方式, 不 仅可以使整体环境得到提升, 同时也为里分公共空间的重 塑提供发展空间。

（2）改善室外热舒适环境。通过增加自然通风和自 然采光来改善热舒适环境质量, 同时也可达到节约资源的 目的。具体可从总体布局和建筑单体两个层次进行改造, 从整体到局部的“渐进式重构”改造方式 [10]。总体上打破 围墙, 梳理巷道的加建和杂物形成良好区域通风道(图9)。 单体上对局部建筑进行架空处理。 
采用斯维尔软件对改造前后的建筑通风和日照进行 仿真模拟计算, 并对模拟结果进行对比。现状风速图显示, 里分内部风环境较差, 内部风速几乎为零 (图10-11), 日照情况不乐观。进行改造后的里分整体风环境得到改善, 这说明打破围墙、梳理巷道, 连通了外界和里分内部, 促 进夏季东南风的灌入。局部挑空, 则利用巷道形成“峡管 效应”, 使得流入气流可以进一步深入里分内。在坤厚里 的西北界面, 沿着中山大道和一元小路建筑布局较东南界 面更封闭, 目的是在冬季能够更好的防风（图12-13）。 总体上, 通过以上策略里分内风环境得到了很好的改善, 街区热岛也得到了缓解。其改造后的日照情况也得到显著 的改善（图14-15）。

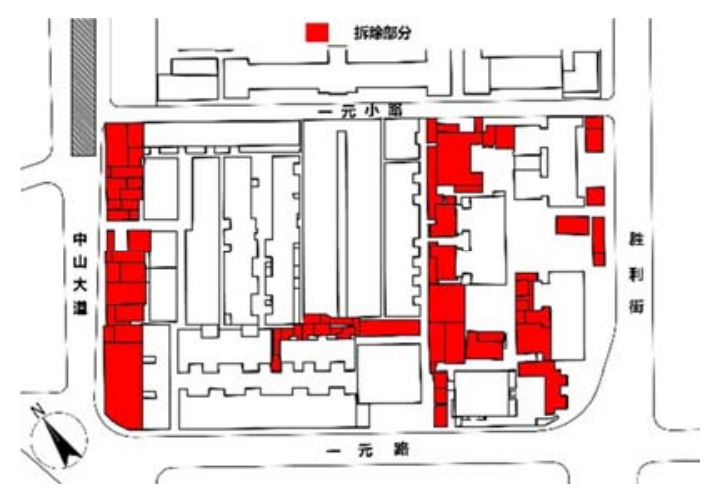

图8 拆除自主加建和质量差的建筑（图片来源：作者自绘）。

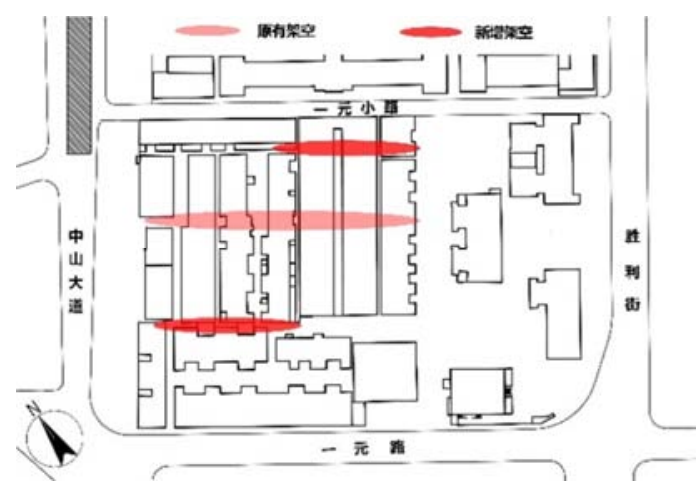

图9 局部架空打破围墙（图片来源：作者自绘）。

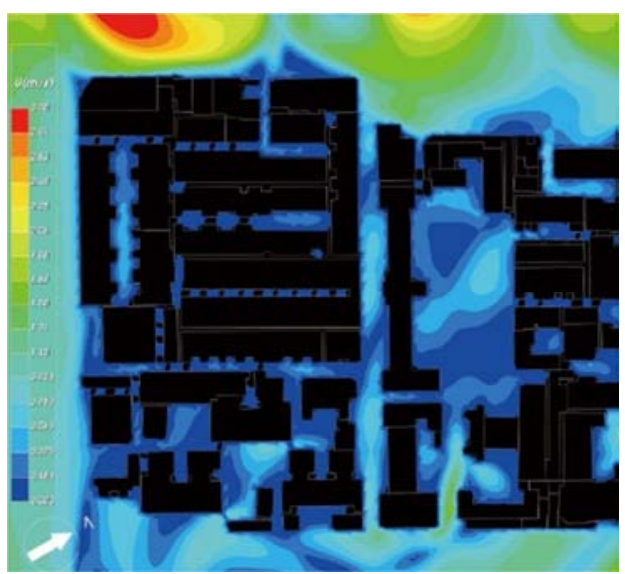

图10 里分建筑现状夏季主导风风速云图。

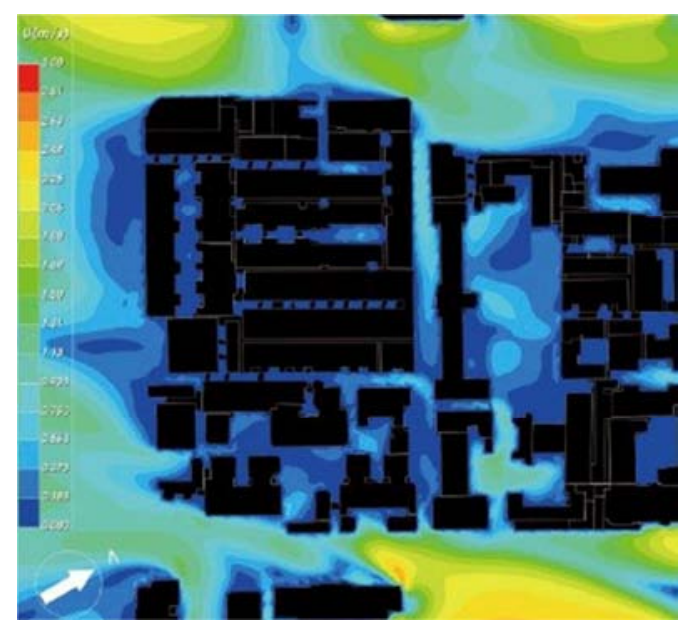

图11 里分建筑现状冬季主导风风速云图。

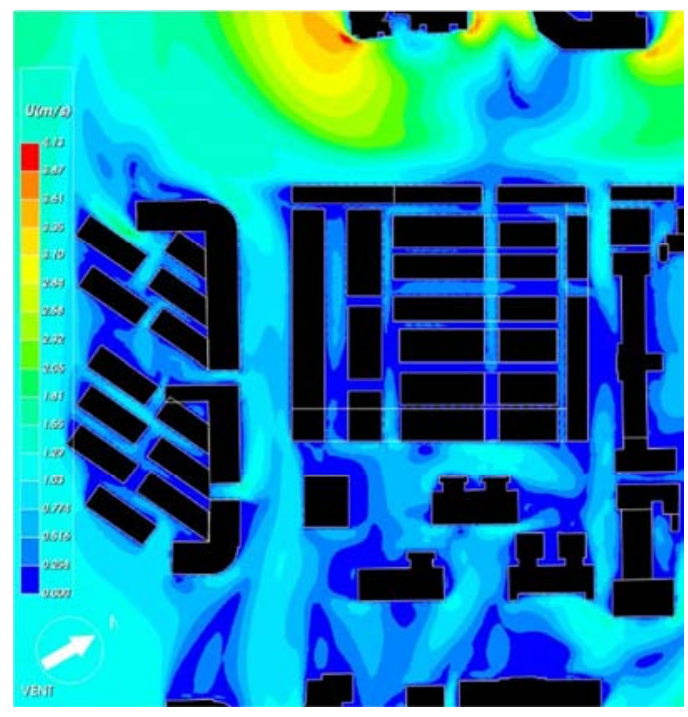

图12 里分建筑改造后夏季主导风风速云图。

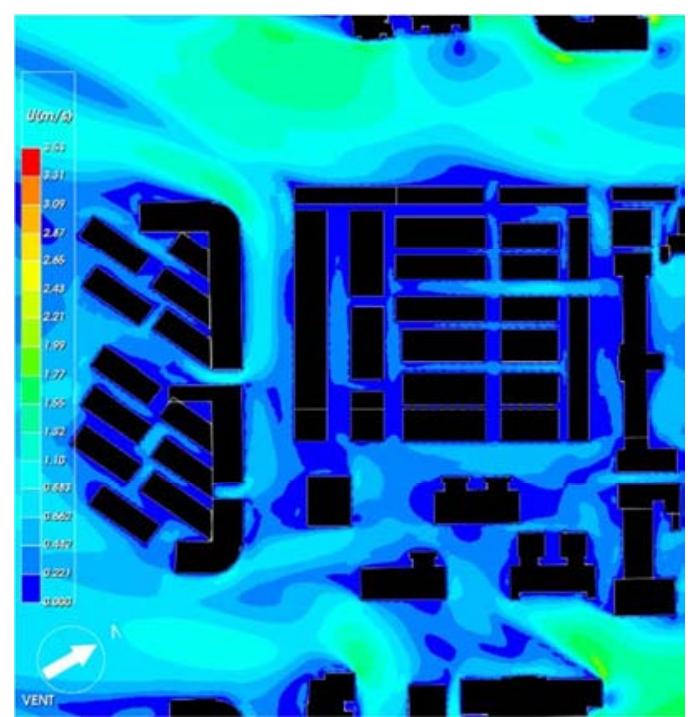

图13 里分建筑改造后冬季主导风风速云图。 


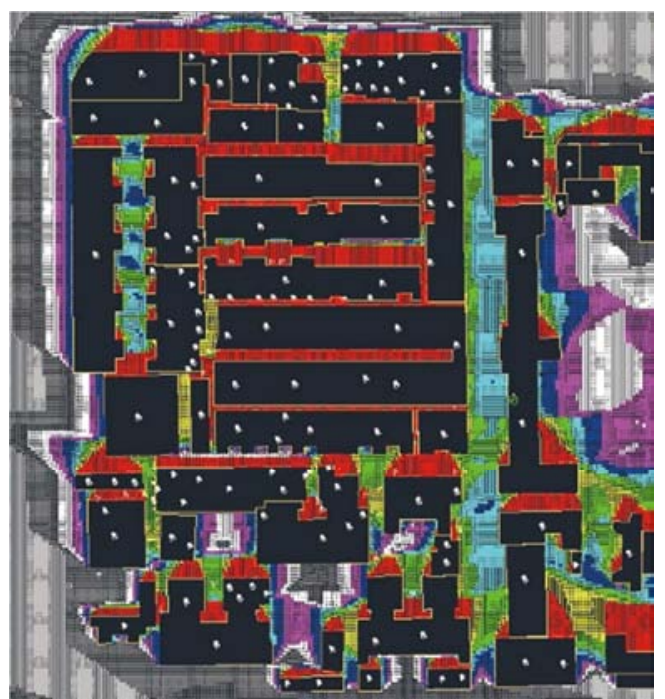

图14 里分建筑日照现状 (图片来源: 软件模拟) 红色 $=0 \mathrm{~h}$ 黄色 $=1 \mathrm{~h}$ 绿色 $=2 \mathrm{~h}$ 青色 $=3 \mathrm{~h}$ 。

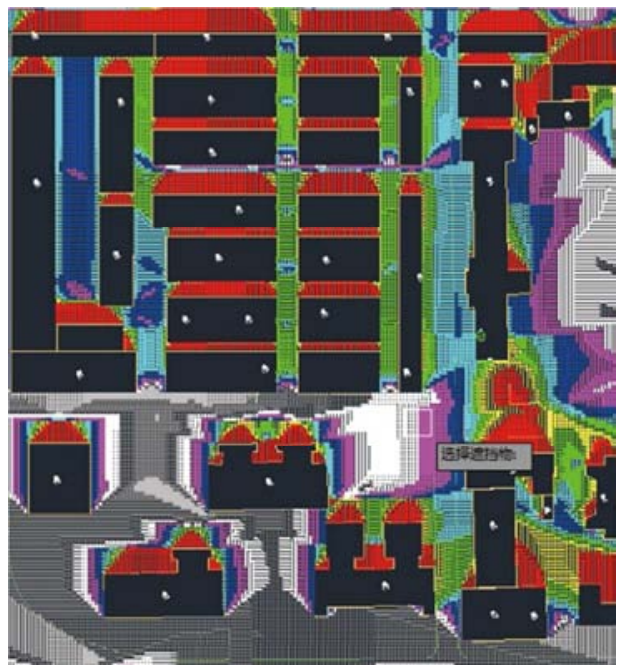

图15 里分建筑日照改造后（图片来源：软件模拟）红色 $=0 \mathrm{~h}$ 黄色 $=1 \mathrm{~h}$ 绿 色 $=2 \mathrm{~h}$ 青色 $=3 \mathrm{~h}$ 。

\section{2. 交通环境疏通}

首先，对交通进行梳理，通过局部架空建筑、打通断 头巷道来疏通、补充里分内的街巷走道, 达到加密巷道路 网的目的（图16）。其次，用“人本位”的理念取代“车本 位”, 建立以人为本的慢行交通系统[11], 即以步行为主、 自行车为辅的出行交通方式, 倡导居民绿色低碳出行。最 后, 解决停车问题。在里分外围道路行道树之间灵活规划 电动车、自行车停车位。在一元小路设置分时段停车位缓 解停车压力。同时还可以结合立体交通来缓解用地紧张和 停车难的矛盾, 避免交通扩散至主要城市道路, 给城市交 通带来压力。

\section{3. 公共空间改造}

（1）空间重塑。公共空间重塑主要包括内部空间和 临界空间两部分。内部空间重塑即利用荒废院落、天井和 拆除加建后的场地重塑里分街巷空间, 针对居民公共活动
类型设置不同特色的街巷空间。临界空间重塑首先是结合 上位规划对临近中山大道质量较差的建筑拆除, 打造成口 袋公园, 为人们提供较为集中的公共开敞空间和休闲场所。 其次, 将临中山大道的里分住宅规划成上居下商的模式, 引入文创等以年轻群体消费和经营为主的商业业态, 重塑 里分活力, 同时缓解年龄的断层现象, 使里分人口结构趋 向健康发展。最后, 将沿着胜利街的独栋历史建筑规划成 社区活动中心和历史展览馆, 靠近胜利街临界空地打造成 城市绿地。不仅可以提升街区内建筑的使用效率, 实现历 史建筑社会转型, 还可以塑造具有场所特征的城市公共空 间（图17）。

（2）基础设施配置。适当增加垃圾集中投放点，同 时加强垃圾分类处理的监管。充分考虑日照和布局, 设置 集中晾晒区。将住户利用巷道空间种植形成的“门前小花 园”规格化, 作为里分内景观小品的补充。适当增加公共 㕑房和公共则所来缓解室内居住空间不足的问题。

(3) 可再生资源的利用。雨水是天然的可再生资源, 可利用蓄水箱等将雨水进行回收处理再利用, 再利用方式 有灌溉花园绿地、清洗路面墙面、充当里分内杂用水等。 武汉市雨量充沛, 有良好的雨水再利用的自然优势。其次 里分内的建筑多为传统的双坡屋顶, 保证了雨水收集在结 构上的可行性，处理好收集管道的隐蔽性问题，即可在不 破坏建筑风貌的前提下充分节约资源和减少经济成本。同 时可以合理使用太阳能热水和太阳能光伏系统, 前者可提 供居民的使用热水, 后者可为里分内的路灯、走廊灯、景 观喷泉等公共设施提供电量。

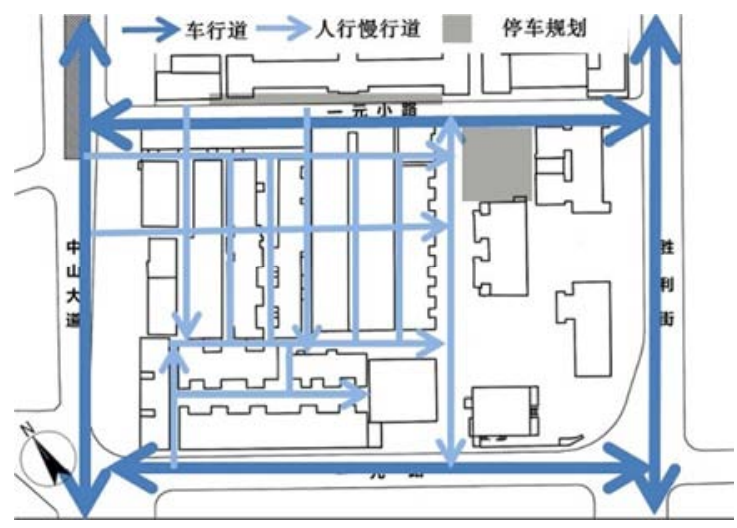

图16 交通梳理（图片来源：作者自绘）。

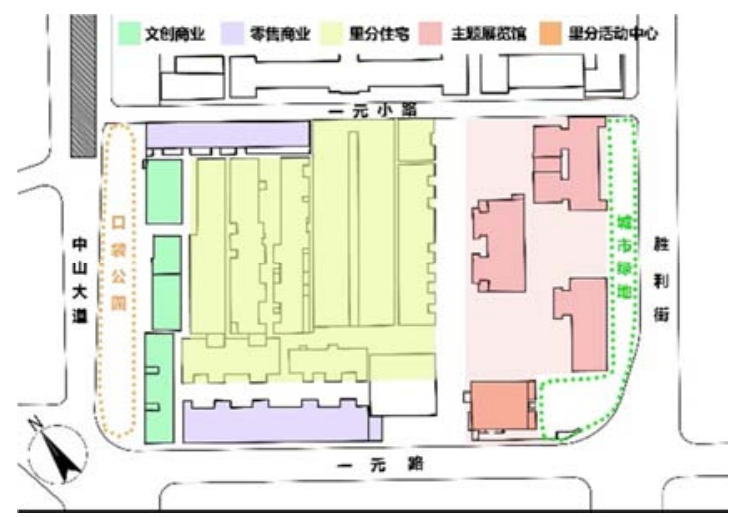

图17 改造后公共空间分布（图片来源：作者自绘）。 


\section{4. 建筑外围护改造}

（1）节能改造。由于建筑外围护结构老化程度不一, 无法一概而论, 因此需要分类讨论。第一类为破损风化较 为严重和整体结构失衡的墙体, 应进行较为彻底的基础墙 改造。可采用节能材料对墙体进行改造加固, 具体结构的 加固方法是在现有的主要建筑结构中增加一层加固的外 墙, 并为外墙添加保温系统[12]。研究表明, 对于夏热冬 冷地区外墙保温层厚度在 $40 \mathrm{~mm}$ 时, 节能率提高是最明显 的, 继续增加变化幅度反而很小 [13], 因此外墙保温层以 $40 \mathrm{~mm}$ 为宜。第二类为整体结构完好仅部分墙体损坏的, 可对墙体进行掏碱修缮, 部分腐蚀砖块用节能砌块进行掏 换来修复破损[14]。门窗部分主要用更换综合密闭性高的 节能门窗（木塑铝窗框）、高效节能玻璃（例如low-e真 空玻璃或绝热玻璃) 的改造措施来提高窗户的保温遮阳性 能。对于具有一定时代特色的门窗（图18）, 应在节能改 良后进行留存或者加装保护性外壳。里分内原有建筑多采 用砖木建造, 使用绿色材料进行改造时, 应注意不要与原 有传统建筑在风格和形式上产生冲突。

(2) 防潮改造。改善建筑内部的居住环境质量：一 方面可以对墙面进行防潮处理来改善建筑底层过于潮湿 的问题。可采用化学注入的方法修复历史建筑因潮湿而损 坏的墙面, 这种方式在发达国家已经被证明对墙体几乎无 影响 [15]。同时还可以通过室外勒脚、明沟的修复, 改善 外墙表层防水性能[7]。另一方面可以通过增加具有拔风性 能的天井来改善住宅内部的采光和通风（图19），增加自 然通风自然采光同时也可达到节约能耗的目的。

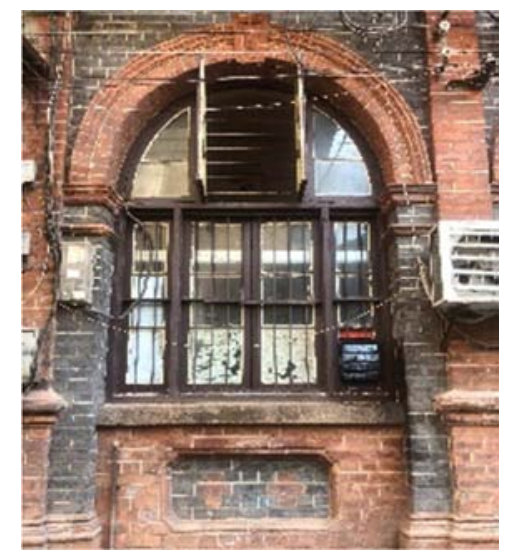

图18 里分内特色窗户（图片来源：作者自摄）。

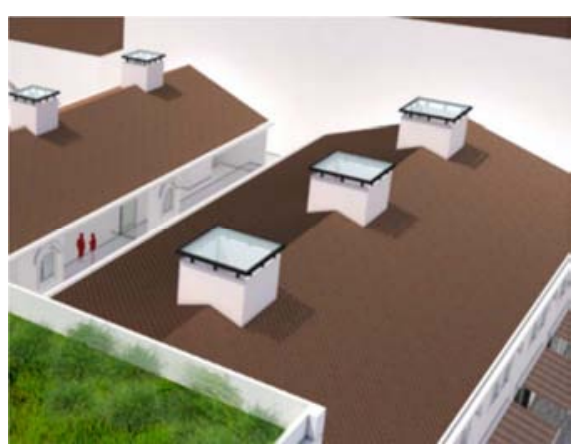

图19 里分建筑内部加天井效果（图片来源：作者自绘）。

\section{4. 结语}

对于里分建筑的绿色更新改造是一个漫长的过程, 需要 逐步完善。在改造过程中要结合街区的实际情况, 对环 境质量、交通、公共空间、建筑外维护结构等方面去进 行深入研究, 以问题为导向, 针对性的选择相应的设计 手法和技术手段进行更新改造。本文通过对坤厚里的深 入分析进行改造, 从多个方面提出了策略, 期望能够为 将来相关改造工程提供相关的借鉴和建议。里分街区及 建筑是一笔珍贵的历史遗产, 适应性的绿色更新改造对 里分建筑存续发展起着关键性的作用, 通过新旧共生使 里分建筑重获生机, 承载新时代的功能, 延续汉口老城 区的文化记忆。

\section{基金项目}

国家自然科学基金项目“滨水街区空间形态与江河风 渗透之“量” “效”关联性研究 以长江中下游城市为例” (51778251）。

\section{参考文献}

[1] 《国务院关于印发“十三五”节能减排综合工作方案的通知。 000014349/2016-00271。

[2] 王海香.LID视角下的里分保护与更新研究——泰兴里为 例 $[J]$.家具与室内装饰,2020(01):92-93。

[3] 王刚, 胥晓雯.里分建筑保护与更新的策略研究一以汉口三 德里为例 [J].中外建筑,2019(12):43-44。

[4] 张念伟,王锟.文化遗产角度下里分建筑保护与更新策略研究 [J].艺术教育,2018(17):215-216。

[5] 张文静.HBIM在里分建筑保护中的应用研究[D].华中科技大 学, 2018。

[6] 杨洋.基于历史街区更新的新旧关系整合设计研究[D]. 华中 科技大学,2019。

[7] 罗睿,彭雷.武汉近代里分住宅更新保护研究——以坤厚里片 区为例 $[J]$.华中建筑,2012,30(06):162-166。

[8] 冯如飞.绿色建筑技术在历史建筑保护与更新中的应用策略 研究[D].郑州大学,2014。

[9] 张刚, 郭玲. 低碳视角下的武汉里分更新 [J]. 城 市,2013(07):32-35。

[10]郭捷.汉口历史里分住宅建筑文化价值与保护研究 [D].武汉 纺织大学, 2020。

[11]汪小琦,李星,乔俊杰,蒋源. 公园城市理念下的成都特色慢行 系统构建研究 [J].规划师,2020,36(19):91-98。

[12]龚翔. 老旧小区改造中的外墙节能设计 [J]. 建 筑,2019(09):73-74。 
[13]陈玢晶,李德智,李启明.夏热冬冷地区既有居住建筑节能改 造综合效益分析[J].建筑科学,2017,33(08):42-48。

[14]余泞秀.天津五大道先农商旅区绿色化更新设计研究 [D]. 天 津大学,2014。

[15]王少媚, 吴黎梅, 王利明.历史建筑墙体防潮技术研究 杭州平远里建筑群为例[A].中国民族建筑研究会.中国民族 建筑研究会第十九届学术年会论文特辑[C].中国民族建筑 研究会:中国民族建筑研究会,2016:9。

\section{作者简介}

郑娇艳 (1996-), 女, 硕士研究生在读。研究方向: 绿 色建筑技术。

陈宏（1967-）, 男, 华中科技大学建筑与城市规划学院 教授, 博导。研究方向: 绿色建筑技术。 